\title{
FICTIONALIA AS MODAL ARTIFACTS
}

\author{
Jeffrey GOODMAN \\ James Madison University Harrisonburg
}

\begin{abstract}
Summary
There is much controversy surrounding the nature of the relation between fictional individuals and possible individuals. Some have argued that no fictional individual is a possible individual; others have argued that (some) fictional individuals just are (merely) possible individuals. In this paper, I offer further grounds for believing the theory of fictional individuals defended by Amie Thomasson, viz., Artifactualism, by arguing that her view best allows one to make sense of this puzzling relation. More specifically, when we realize that the view allows for an identification of merely possible individuals with fictional individuals, we see that the utility, and hence the level of credence lent to Artifactualism, is increased. After arguing for this thesis, I respond to three of the most pressing worries.
\end{abstract}

\section{Introduction}

Sherlock Holmes is an individual that sprang, in some sense, from the mind of Sir Conan Doyle. But Holmes is a fictional individual; he does not exist. Or so it seems. But could Holmes have existed? Is he among the realm of possible individuals? The intrinsically identical iron spheres first discussed by Max Black in his famous (1952), taken by some to refute one version of Leibniz's Law, seemingly do not exist either; the spheres are merely possible individuals. And the spheres are individuals that seem tightly analogous, in various other important ways, to Sherlock Holmes. For example, they may not be the subject of an elaborate work of fiction-they simply are individuals discussed by a philosopher in a fairly short narrative meant to enlighten our thinking about metaphysics and logic — but the spheres also sprang, in some sense, from the mind of Black.

Let us call the problem embodied by the following question the fictionalia/possibilia problem: What is the nature of the relation between fictional individuals (or fictionalia) and merely possible individuals (or possibilia)? 
Some (famously, Saul Kripke) have argued that the correct answer to this problem is that no fictional individual is a possibilium. ${ }^{1}$ Others (famously, David Lewis) have defended the claim that taking (some) fictionalia to be types of possibilia provides the correct answer. ${ }^{2}$ In this paper, I wish to draw on the parallels between fictionalia and possibilia to argue for a different sort of view. I wish to defend the solution that all possibilia are fictionalia. But I do not wish to argue that any view of fictionalia will allow for such an identification; it is only the theory attributable to Amie Thomasson, viz., Artifactualism, ${ }^{3}$ that can provide adequate resources to solve the fictionalia/possibilia problem in this way. And this service that her view is able to provide, I maintain, lends credence to Artifactualism as the correct theory of fictionalia. These are the central theses of this paper.

I will begin by presenting and explaining two of the most prominent views concerning the relation between possibilia and fictionalia (viz., Lewisianism and Artifactualism). I next wish to defend the argument in favor of the identification thesis stated above. Some not-too-distant relatives of this sort of solution to the fictionalialpossibilia problem (viz., Neo-Meinongianism and Modal Fictionalism) already exist, however, so I next intend to present these views along with an explanation of their inadequacy. I will then respond to three of the most pressing sorts of worries for my central theses.

2. How possibilists and some actualists solve the fictionalialpossibilia problem

Let us call the philosopher who endorses the following thesis an actualist ${ }^{4}$ : No merely possible, nonactual individuals (i.e., possibilia) ${ }^{5}$ exist. So, the

1. See Kripke 1980, $157 f$.

2. See Lewis 1978

3. I have in mind the view she presents and defends in her (1999). Others, though, have defended Artifactualism at length-Nathan Salmon (1998), e.g.

4. This is, in some ways, not a standard usage of this label. 'Actualist' often refers to one who believes a related thesis about the non-existence of (whole) merely possible worlds. Similar remarks apply below to the usage of 'possibilist'. More to the point, there is no unique way of drawing the distinction between actualists and possibilists. Just consider what follows to be one theoretically interesting way. For an extremely helpful, accessible discussion of other important ways to cash out an actualist/possibilist distinction, see Takashi Yagisawa (2008).

5. 'Possibilia' in this paper will mean merely possible individuals. Of course, all actual individuals are possible individuals, but I'll be reserving this term for nonactual possible individuals. 
actualist denies, for instance, that there are, e.g.: talking donkeys; 50-foot tall women; and ducks with wheels for their appendages. The actualist thinks it possible that there be such things, but in fact there aren't. ${ }^{6}$ She asserts that reality is exhausted by the things there are- that which is actual —and that which merely could be-that which is possible but nonactual-is nothing at all. ${ }^{7}$

Next consider the possibilist. The possibilist rejects the thesis of the actualist. The possibilist believes that there are some merely possible individuals in existence. But the possibilist further believes, in accord with the actualist, that reality is exhausted by the things there are. How can this be? Aren't possibilia the sorts of things that, by their very nature, do not in fact exist, i.e., are not part of reality? Well, the possibilist adds the following semantic theses by way of reconciliation. The term 'actual' is an indexical. For us, it denotes our world, our corner of reality. But there are other worlds, other corners of reality, and those worlds (nonactual for us) are actual for the denizens there. Further, the possibilist adds that we usually restrict the scope of our quantifiers in everyday parlance about what things exist. When we say 'There are no 50 -foot tall women', we ordinarily just mean: there are no 50 -foot tall women in our corner of reality. There are 50 -foot tall women, according to the possibilist, just none here. Thus, this sort of philosopher may also hold that reality is exhausted by the things there are-it's just that some of the things there are are not in our corner of reality, not here at our world. Such off-world individuals are identified by the possibilist with the set of possibilia. ${ }^{8}$

Now let us consider a possibilist who further endorses the following view of fictionalia. Call this person a Lewisian. ${ }^{9}$ A Lewisian holds that

6. In this paper I will be using the verb 'exist' and 'is' (and their cognates) interchangeably, at least until I get to an explicit discussion of Meinong and Neo-Meinongian views about fictionalia and possibilia.

7. I think the slogan "reality is exhausted by the things there are" is helpful here, but it isn't altogether perfect; it suggests that questions about what there is to reality can be settled purely by ontology. Someone who accepts the so-called "truthmaker principle" would likely take the slogan to be literally true, but many metaphysicians would maintain that a list of all the things that exist would still leave out some of what comprises reality, e.g., truths concerning which things have which properties. Thanks to Ted Sider for pointing this out.

8. Not every possibilist accepts this indexical theory of actuality. Lewis (1986) argues for this view, and this fits his particular brand of modal reductionism. See Phillip Bricker (2006), however, for a version of possibilism that eschews an indexical theory of actuality.

9. The view I will be calling Lewisianism is very close to the sort of view espoused by Lewis (1978) - hence the name for the view. There may be some things I attribute to the Lewisian, however, that Lewis himself would not accept. 
some fictionalia, specifically, all the ones having co-instantiable properties, just are possibilia. So, according to Lewisianism, Sherlock Holmes exists. Holmes is not here, but he does exist in another corner of reality. He is a flesh and blood, pipe-smoking, cocaine-using solver of crimes in some alternate possible world. Holmes, like many fictional individuals, does not have properties that fail to be co-instantiable (or so we'll assume for present purposes); that is, Holmes is not an impossible individual. Impossibilia, according to Lewisians, exist in no corner of reality.

So, one answer to the fictionalia/possibilia problem is provided by Lewisianism: fictionalia just are a type of possibilia. When we engage in discourse about putative fictionalia having co-instantiable properties, it turns out on this view that we are simply speaking of certain extant individuals that are off-world relative to us; when we engage in discourse about putative fictionalia that have properties that fail to be co-instantiable, we are speaking about nothing at all.

There are some well-known problems with the viability of this sort of solution to the fictionalialpossibilia problem. The following oft-discussed difficulty ${ }^{10}$ seems to me to be sufficient to refute Lewisianism (although I will not spend time defending that claim here). If the fictional individual Sherlock Holmes, e.g., is to be identified with a possibilium, then it must be the case that there is some unique flesh and blood, pipe-smoking, cocaine-using crime solver in an alternate possible world that is Holmes. But there is no such thing. In fact, there are an infinite number of merely possible entities that satisfy all that is true about Holmes in the Holmes stories, and any identification of Holmes with exactly one of these individuals would be utterly arbitrary; the identification of Holmes with more than one of these individuals, or the totality of them, would be absurd.

This failure motivates an alternate solution to the fictionalialpossibilia problem, an actualist sort of solution. ${ }^{11}$ There are a few ways such a solution might proceed. One way is Kripkeanism - the view that not only do fictionalia fail to exist (here in the one and only world), they are one and all impossible. ${ }^{12}$ I intend to briefly say something about the viability of

10. See, e.g., Alvin Plantinga (1974, 154f.) and Amie Thomasson (1999, 17f.) for a discussion of this issue.

11. Even with the success of the just-discussed objection, it may be that possibilism is still true. Perhaps the possibilist just needs a different sort of account of fictionalia than the one given by Lewisianism. I will not take the time here, however, to explore how such an account might go.

12. I call this view Kripkeanism because it is suggested by Kripke (1980, 157f.). Kripke himself seems not to be a Kripkean; he seems to be an Artifactualist of some sort. At least, he seems to endorse Artifactualism in his (1973). 
this solution at the start of Section 4. Another sort of anti-realist (about fictionalia) solution that is clearly consistent with actualism is Modal Fictionalism. I will discuss that view in Section 5. The sorts of actualist solutions that I wish to discuss at length now, however, are the ones that are consistent with Amie Thomasson's Artifactualism.

Artifactualism maintains that fictional individuals exist; they are not spatiotemporal or concrete entities (it is thus sometimes said that they are not "real"), but they are extant bits of abstracta created by the authors who first wrote (or spoke, etc.) about them. Fictional individuals are thus understood as artifacts. They are contingent actualia whose existence depends in various ways on (the intentions of various) authors, (the intentions present in) appropriate audiences, and physical instances of story-copies that mention them. ${ }^{13}$

Unlike the above discussion of Lewisianism, I wish to explicitly discuss the main motivation for Artifactualism; this will prove to be crucial to my defense of the central theses of this paper. The locus classicus of the argument that has convinced most Artifactualists was presented by Peter van Inwagen (2001) (although it appears that van Inwagen himself is not a card-carrying Artifactualist). ${ }^{14}$ Van Inwagen first asks us to consider sentences like the following:

C: Sherlock Holmes is a character created by Conan Doyle.

F: Sherlock Holmes is a more famous fictional detective than Nancy Drew.

A: Sherlock Holmes appears in the story "A Scandal in Bohemia".

C, F, and A are, to use van Inwagen's terminology, examples of sentences of literary criticism. That is, they are part of "all 'informed' discourse about the nature, content, and value of literary works". ${ }^{15}$ I shall call sentences relevantly similar to $\mathrm{C}, \mathrm{F}$ and $\mathrm{A}$ extra-fiction sentences. An extra-fiction sentence is one that, at least apparently, associates via the ordinary exemplification relation some property with a fictional individual. This is not, according to van Inwagen, the only way a property may (apparently) be

13. Again, the most thorough presentation and defense of Artifactualism, along with an explication of these alleged dependence relations, can be found in Thomasson (1999).

14. While van Inwagen thinks fictionalia are contingent abstracta, he seems to deny in his (2003) that they come about due to our activities in the way that Thomasson (1999) alleges.

15. Van Inwagen 2001, 45. The displayed sentences in the following paraphrase of van Inwagen's argument are my own. 
associated with a fictional individual, however. Some properties come to be associated with a fictional individual in virtue of what is "true in world of the fiction(s)" that mention that individual; these are the properties the individual holds. ${ }^{16}$ Sentences expressing this latter sort of association between a fictional individual and a property I shall call intra-fiction sentences. The following are instances of this type of sentence:

U: Sherlock Holmes is a cocaine-user.

P: Sherlock Holmes smokes a pipe.

S: Sherlock Holmes is a crime-solver.

Now, the crux of van Inwagen's argument is this: there appears to either be no way whatsoever, or at least no theoretically attractive way, to provide the semantics of extra-fiction sentences without quantifying over "creatures of fiction", e.g., fictional individuals such as Sherlock Holmes. That is, $\mathrm{C}, \mathrm{F}$ and $\mathrm{A}$ - unlike $\mathrm{U}, \mathrm{P}$, and $\mathrm{S}$ - are the sorts of sentences that are not about any property that any literary work associates with Holmes; they are sentences that appear to be about properties exemplified by Holmes simpliciter (properties associated with Holmes from a "real world" perspective). But the best explanation (that is, the simplest, most elegant sort of semantic account) for the fact that C, F, and A are all meaningful and all true is that appearances are not deceiving here. Sherlock Holmes is an extant individual that in fact has the properties expressed by the predicates appearing in those sentences. C, F, and A ought to be taken at face value. And since we are epistemically justified in accepting the concomitant ontological commitments of our best explanations, we are justified in committing ourselves to the existence of Sherlock Holmes.

Now, the conclusion of this argument is completely general. Thus, an Artifactualist who accepts van Inwagen's line will assert that all of our discourse about putatively fictional individuals is discourse about extant individuals. ${ }^{17}$ Sherlock Holmes and Cinderella and James Tiberius Kirk are all denizens of our world, the only world. But they are not flesh and blood crime-solvers or ball-attendees or starship captains. They are abstract

16. This is van Inwagen's (2003) terminology. His (2001) terminology is different; the holding relation in this earlier work is called 'ascription'. For a full discussion of the nature of the ascription relation see his (2001, especially 49-54).

17. Some care is needed here. Even some realists about fictionalia believe that we may only succeed in referring to fictionalia when the appropriate intentions to refer are present in us. See David Braun (2005) for an example of a realist of this sort. 
entities, and as such, are not the sorts of things that can possibly solve crimes, attend balls, and captain starships. In fact, they do not have any of the properties they hold in the fictions that mention them; the properties they have, rather, are the properties expressed in the true extra-fiction sentences that mention them.

So, one way to state an Artifactualist solution to the fictionalia/possibilia problem is this: No fictionalia are possibilia (because the former actually exist while the latter lack existence simpliciter). Now, this sounds on the face of it to be the Kripkean solution, but of course it is distinct. An Artifactualist would assert that all fictionalia are possibilia in the sense that anything that actually exists possibly exists; the claim here is just that none are merely possible (nonactual) individuals.

\section{An argument for fictionalia as modal artifacts}

So, Artifactualism identifies all fictionalia with abstract, yet contingent actualia. ${ }^{18}$ This is one way to understand her solution to the fictionalial possibilia problem. But there is another sort of solution consistent with Artifactualism that is more enlightening regarding the nature of the fictionalia/possibilia relation-one that informs our modal theorizing and thereby lends credence to Artifactualism. Let me explain.

While actualists deny the existence of nonactual possibilia, most wish to claim that there are nonetheless (extant) individuals that can go proxy for-serve as surrogates for-such (nonexistent) entities. That is, they realize that our modal discourse requires truthmakers, that we sometimes say true things that seem on the face of it to commit us to possibilia. Various types of actualia have been proposed as such truthmakers (properties, say some, words, say others). ${ }^{19}$ I believe that the best sorts of actualia to propose as the surrogates for the genuine possibilia of the possibilist are the fictionalia of the Artifactualist.

18. And assuming—safely it seems! - that our world is not an impossible world, all Artifactualist fictionalia will have co-instantiable properties. A fictional work about a detective who is not a detective - call him Sholumbo-would not be about an individual that both has and lacks the property being a detective; Sholumbo just lacks this property. Sholumbo holds these incompatible properties, but that, of course, entails nothing about the impossibility of our world, just the impossibility of the "fictional world" Sholumbo inhabits.

19. See, e.g., Alvin Plantinga (1974) for a view on which properties are the surrogates for possibilia. It's open to someone who endorses the view of modality known as Linguistic Ersatzism (e.g., Theodore Sider 2002) to hold that words are the proper surrogates for possibilia. 
We often take certain individuals to be merely possible for the sake of some (philosophical or quasi-philosophical) discussion. That is, we often do modal storytelling. We do this whenever we use counterexamples or thought experiments or consider counterfactual scenarios to advance our philosophical (or scientific) understanding. Now, simply put, I think this type of discourse commits us to fictionalia of the Artifactualist variety. But if these sorts of fictional individuals are playing these roles in our modal theorizing, we ought to admit that possibilia just are such fictionalia.

It is helpful to think about the following regimented version of the argument just given:

\section{The Argument for Modal Artifactualism}

1. A thought experiment (taken to include counterexamples and other sorts of counterfactual scenarios) is just a primitive sort of fiction.

2. The individuals mentioned in fictions exist.

3. Therefore, the individuals mentioned in thought experiments exist.

4. If thought-experiment individuals exist, then discourse about possibilia just is discourse about fictionalia of the sort posited by the Artifactualist.

5. Therefore, discourse about possibilia just is discourse about fictionalia of the sort posited by the Artifactualist.

Call an Artifactualist who supplements her view of fictionalia with the conclusion of this argument a Modal Artifactualist. This identification of possibilia with fictionalia provides a valuable service. It allows us to see that we do indeed have some actual world surrogates that are suited to play the role of nonactual possibilia. We need truthmakers to ground our modal discourse, to make sense of our modal theorizing that we engage in via thought experiments and counterfactuals and counterexamples, and with fictionalia of the Artifactualist variety, we have that. This serviceability lends credence to the view; whatever its merits already, we have further reason to believe Artifactualism once we realize it's potential scope. (Which is not to say that it can provide every service we are looking for when it comes to surrogates for possibilia-more on this in Section 6.) Now, perhaps other actualist views of fictionalia are at least as serviceable in this regard, or even more so. In that case, they would need to be adjudicated on other grounds. But I intend to argue in Section 5 that either 
the prominent rival views fail to be as serviceable as Artifactualism, or they are epistemically less worthwhile for independent reasons.

\section{A discussion of the premises of the Argument for Modal Artifactualism, with a critical focus on premise 4}

I believe the Argument for Modal Artifactualism is sound. I thus believe that Kripkeanism must be false. But what justifies the premises of this argument? Premise 1 is supported by some very natural intuitions about the nature of thought experiments (construed in a broad sense). At least when one begins with the intuitively more sensible ontological framework of the actualist, one then wonders: What could philosophers be doing when they engage in relating thought experiments if they are not just telling stories, creating primitive (and often very short) works of fiction? ${ }^{20}$ No other option seems plausible. Premise 2 is supported by van Inwagen's line of reasoning discussed in Section 2, and his argument there appears sound. There are true extra-hypothetical sentences about thought-experiment individuals just as there are true extra-fiction sentences about traditional fictionalia. Here are some examples of true extra-hypothetical sentences:

L: The iron spheres that allegedly constitute a counterexample to one version of Leibniz's Law were first discussed by Max Black.

$\mathrm{H}$ : The intrinsically identical iron spheres are hypothetical individuals.

M: Many philosophers, but few laymen, have heard about Black's iron spheres.

Applying van Inwagen's line, it seems that the best way to understand $\mathrm{L}, \mathrm{H}$, and $\mathrm{M}$, and sentences of their ilk, is to take them at face value. ${ }^{21}$

20. I will be using the expression 'thought experiment' in a very liberal way throughout this paper; any imaginative scenario in which some merely possible situation is entertained will count. Even when 'thought experiment' is used in a more restrictive, technical sense (e.g., a method used by philosophers and scientists alike to arrive at new information by considering hypothetical scenarios), it seems the relevant similarities between thought-experiment narratives (and their characters) and fictional narratives (and their characters) are many. For further discussion of these similarities, see Charles Cross (1995), David Davies (2007), and Roy Sorensen (1992, especially 246ff.). For an extended discussion regarding some relevant dissimilarities between thought-experiment characters and fictional characters, see Alberto Voltolini (1995).

21. I don't think taking them at face value, as true simpliciter, thereby commits us to any 
Contrary to some initial intuitions, then, it follows that we are quantifying over extant bits of abstract actualia when we talk about Black's iron spheres. And these results are perfectly general. Black's iron spheres, Sidney Shoemaker's Brownson, ${ }^{22}$ and Frank Jackson's brilliant neurophysiologist, Mary, ${ }^{23}$ are all extant individuals. But these are not (despite what we call them) individuals made of iron or flesh and blood. They are abstract entities, and as such, are not the sorts of things that can possibly be made of iron or flesh and blood. They in fact have none of the properties associated with them in the thought experiments that mention them; rather, thoughtexperiment individuals (merely) hold the properties associated with them by the authors of the modal stories that mention them.

But Premise 4 of the above argument is the one that requires the most consideration. Why think it's true? I claim that all discourse about possibilia is really just discourse about Artifactualist fictionalia because such fictionalia are best-suited to stand in as surrogates for genuine possibilia. But Kit Fine has provided a seemingly quite powerful argument for thinking that discourse about possibilia cannot turn out to be discourse about any kind of actual world surrogate whatsoever. Fine states:

Can [an actualist] maintain that possibilia are really just Ys, for some actualistically acceptable description Y (i.e., for some description that makes no reference to merely possible objects)? ... Could not every possible $\mathrm{X}$ be identical to an actual $Y$, for some actualistically acceptable description Y?

It seems to me that no view of this sort can be correct. Suppose, to fix our ideas, that it is maintained that every (merely) possible person is identical to an actual property—one perhaps that specifies its 'essence'. Consider now a possible person. Then it is possibly a person. But no property is possibly a person and so no possible person is identical to a property: for there is a possibility for the one, namely that of being a person, which is not a possibility for the other. ${ }^{24}$

particular theory of definite descriptions, specifically, it doesn't commit us to a Russellian understanding of 'the iron spheres'. Pace Russell, true sentences using that expression may fail to entail that there exists something which is spherical and iron. In fact, I think a theory of definite descriptions which places definite descriptions semantically on a par with proper names (at least in some contexts) is correct. For the details of how such a view might go, see Keith Donnellan (1966).

22. Discussed in Shoemaker 1963, $23 \mathrm{f}$.

23. Discussed in Jackson 1982, 130.

24. Fine 2003, 163; the emphasis is my own. 
This argument, however, does not successfully constitute grounds to reject Premise 4. A (merely) possible person for the Modal Artifactualist would not be considered, as Fine infers, possibly a person; the entities that serve as surrogates for merely possible people, according to this view, do not have the modal property in question. (Artifactualist fictionalia do not lack modal properties altogether, but insofar as each is an abstractum, each is essentially an abstractum, hence not possibly made of flesh and blood, hence not possibly a person, etc.) But this is no theoretical drawback. While the fictionalia-cum-possibilia do not have any of the modal properties associated with them by their respective thought experiments, they nonetheless are intimately associated with such modal properties via the holding relation. And this association is all that's required to preserve the core intuitions we have about possibilia such as (Shoemaker's) Brownson or (Jackson's) Mary, e.g. While Brownson is not possibly a person, he holds the property personhood in the counterfactual scenario described (that is, he is a person in Shoemaker's thought experiment just as Holmes is a detective in Conan Doyle's work). And this is precisely the right thing to say about such an individual, I believe. Maintaining that these actual individuals (viz., the Artifactualist's fictionalia) are what play the theoretical role of genuine possibilia (and thereby adhering to the slogan: "possibilia just are fictionalia") seems to be the only plausible way to simultaneously maintain both the intuition that merely possible (nonactual) individuals do not ("really") exist (because the only concrete, spatiotemporal entities in existence are those in the one and only actual world) and the intuition that possibilia are intimately associated with the properties we take them to be associated with (because there are perfectly acceptable actual-world surrogates playing the possibilia role and holding the relevant properties).

While Fine's argument fails to undermine premise 4, more still needs to be said about the positive motivation for that premise. Why think that the surrogates on offer from the Artifactualist theory of fictionalia are the actualia best-suited to play the role of genuine possibilia? Well, some motivation can be found in the work of Charles Cross (1995). ${ }^{25}$ Cross

25. Cross merely suggests the identification of possibilia with fictionalia that I am explicitly endorsing here. He explicitly states:

Having postulated fictional characters we might, like Sorensen, simply classify thought experiments as stories. Thought experiment characters would then turn out to be a subclass of fictional characters, but I see no need to make the move that leads to this result. What is important are the logical parallels between stories and thought experimens ... (Cross 1995, 354) 
maintains that understanding discourse about possibilia as discourse about Artifactualist fictionalia provides us with a straightforward way to resolve certain apparent absurdities that would otherwise arise in our modal thinking. For instance, in our discourse about Sherlock Holmes, we may simultaneously maintain that

C: Sherlock Holmes was created by Conan Doyle.

and

O: Sherlock Holmes must have been the offspring of Mr. and Mrs. Holmes.

yet this pair seems jointly inconsistent on its face. But given Artifactualism, the apparent conflict dissolves. It's simply not the case that Holmes both has the property mentioned in $\mathrm{C}$ yet thereby lacks that very same property given the truth of $\mathrm{O}$. Rather, Holmes has the property mentioned in $\mathrm{C}$ and also has the following perfectly compatible property suggested by O: holding the property not being created by Conan Doyle. In a perfectly analogous way, the apparent absurdity of maintaining both

$\mathrm{N}$ : No person has ever seen, visited or thought about the iron spheres discussed by Black in his famous thought experiment.

and

T: Max Black has thought about the intrinsically identical iron spheres many times.

dissolves if we adopt Modal Artifactualism. The properties had by the individuals in question, specifically, holding the property never being thought about by anyone and being thought about by Black many times are, of course, perfectly compatible. ${ }^{26}$

26. The results of Cross' paper show that we need to revise, to some extent, our thinking about how thought experiments and counterexamples work. He argues there that the iron-sphere story told by Black does not constitute a counterexample to Leibniz's Law in the sense that it fails to constitute a story whose inter-hypothetical details contradict Leibniz's Law. But Cross further argues that the extra-hypothetical facts about the (abstract, so-called) iron spheres that Black creates in telling his story do succeed in refuting one version of Leibniz's Law. That is, the 


\section{Modal Artifactualism vs. some closely-related rival views about possibilia and fictionalia}

What's novel about Modal Artifactualism is not that it takes the metaphysical grounds for our discourse about possibilia to be facts about actualia, but that the actualia in question are different in kind from the possibilia surrogates defended by other prominent metaphysicians thinking about these matters. Taking the surrogates for possibilia to be the fictionalia of the Artifactualist variety allowed us to avoid the trouble presented by Fine's argument. But there are other metaphysicians who maintain that possibilia are (abstract) individuals and can seemingly also provide a plausible reply to the sort of worry Fine presents. In the end, though, I believe Modal Artifactualism is preferable to these views.

I claimed that credence is lent to Artifactualism by the modal service it can provide. However, one of the most serious rivals to Modal Artifactualism, Neo-Meinongianism, can also allegedly provide such a service. In fact I do not think that's the case. But to defend this charge of inadequacy, I need to first explain what Neo-Meinongianism is. ${ }^{27}$

Neo-Meinongianism presents a third fundamental option in modal metaphysics, that is, an alternative to actualism (as presented) and possibilism (as presented). Until now, I have been treating actualism as the view that reality is exhausted by actualia and possibilism as the denial of this thesis (further, I have been treating the cognates of 'exists' and 'to be' as synonyms). But the Neo-Meinongian believes that to understand reality in this way is to gloss over the fact that there are really two modes of reality, existence and mere being. The Neo-Meinongian thinks that that which is

spheres, according to Cross, are not indiscernible given what's true in Black's story, but they are indiscernible from a "real world" perspective. An upshot of all this, I believe, is that usually when we engage in modal theorizing, the properties that are germane are the ones held (and not had) by the hypothetical individuals in question, precisely those properties the author of the thought experiment stipulatively attaches to the individuals for the purpose of carrying out some bit of modal theorizing. But there are rare cases where some properties that are had and not held by the relevant individuals will turn out to do some important theoretical work.

27. This expression, like 'actualism' and 'possibilism', should be understood as a term of art here. I merely intend to be carving out three tenable views in modal metaphysics. It is less important to me how these terms are usually applied or whether or not the ways I am using them in this paper serve to pick out the precise views of any theorist. That said, both Terence Parsons (1980) and Edward Zalta (1983) present and defend theories of individuals that clearly seem to count as Neo-Meinongian. However, just as Lewis might not be a Lewisian and Kripke not a Kripkean, it is not crucial to the present paper whether Zalta or Parsons are truly NeoMeinongians. 
actual is that which has (i.e., exemplifies) existence (and in this sense, she is a sort of actualist), but she further holds that there is a non-actual realm constituted by individuals that lack existence but merely are. According to Neo-Meinongianism, platonic, non-contingent abstracta comprise the realm of individuals that merely are, and (some of) these (non-actual) individuals comprise the realm of possibilia (and in this sense, the view is a form of possibilism). ${ }^{28}$

I do not wish to consider the motivations for this view. I think the prominent versions of Neo-Meinongianism found in the philosophical literature are at least internally consistent. Rather, what I wish to discuss are two reasons why I think Modal Artifactualism is a preferable theory of possibilia.

Firstly, I think Neo-Meinongianism is epistemically less worthwhile for reasons not having to do with the service it can allegedly provide regarding possibilia. Specifically, the view does violence to the idea that the individuals mentioned in thought experiments are our creations and what properties that get associated with these individuals is in an important way up to us. It seems implausible to me that we are tapping into a realm of eternal, platonic abstracta when we tell modal stories; that is, it seems implausible to think that we discover possibilia (and discover what properties are associated with them). I think a reasonable theory of possibilia must be one that accounts for the way in which we make up the realm of possibilia as we go. ${ }^{29}$ This, of course, is not to say we are utterly unconstrained in our creative activities; we don't have free rein over the properties had by possibilia. For instance, we cannot create a possible individual that both has and lacks F-ness, or one that otherwise exempli-

28. This view in fact outstrips possibilism, though, as far as what constitutes reality, because Neo-Meinongians believe in impossible individuals (round squares and detectives who are not detectives) with mere being.

29. It is for these reasons that I am no Plantingean either. Plantingeans are actualists that argue for an identification of possibilia to a very different sort of surrogate, viz., haecceities, or individual essences. These are eternal, necessarily existing "individualistic" properties that are never in fact exemplified. On this view, our talk about Brownson, e.g., is to be understood as talk about the (never-exemplified) property being Brownson. It thus follows on this view that Shoemaker literally discovered Brownson in the Platonic realm and then described what he found there. (It's a good thing for the history of philosophy that he focused on the right sorts of details!) Much has been said by way of making these results of Neo-Meinongianism and Plantingeanism seem less difficult to swallow, but why swallow them at all when we have in Modal Artifactualism a view that doesn't entail this odd result in the first place? NB: This usage of 'Plantingeanism' derives largely from the work of Plantinga (1974), but it's not crucial to the present project that Plantinga himself turns out to be a Plantingean. 
fies some metaphysically impossible property. Now, we can-and often do-create individuals that hold both $\mathrm{F}$ and not-F, or ones that hold metaphysically impossible properties, but these are individuals that serve as surrogates for impossible individuals.

Modal Artifactualism is the best way to make sense of the Kripkean insight that certain facts about possibilia (such as facts about "trans-world" identity relations) are determined stipulatively. One may hold that possibilia are eternal, platonic abstracta, and hence may have reason to deny premise 1 of the argument for Modal Artifactualism, but this only serves to promote the wrongheaded notion that we are able to peer into the goings-on of possibilia as if using a magic telescope. It seems to me to be literally true that Brownson came from the imagination of Shoemaker, and that the intrinsically identical spheres came from the mind of Black (just as it's literally true that Holmes came from the mind of Conan Doyle) due to the philosophical storytelling each engaged in. And I may succeed in referring to the numerically same Brownson or the numerically same spheres in virtue of stipulating (perhaps tacitly) that that's what I intend to refer to when delivering a lecture on these famous thought experiments to my students.

The second worry for Neo-Meinongianism is aimed to show that the view cannot in fact provide the sort of modal service that Modal Artifactualism can provide. This begins with the realization that the abstract, non-actual individuals that are identified with possibilia seemingly cannot be properly individuated.

The Neo-Meinongian makes the further claim that possible individuals are those entities that correspond in the right way to (eternal, platonic) sets of properties. ${ }^{30}$ So, some reflection on the nature of these sorts of individuals allows us to see how this view may also avoid Fine's worry; possibilia need not be entities that correspond to the intuitively incorrect sorts of (sets of) modal properties. For instance, according to Edward Zalta's version of Neo-Meinongianism, individuals may be associated with properties either via an exemplification or an encoding relation. Possibilia may encode properties that they do not exemplify, and thus a reply to Fine that parallels the reply made by the Modal Artifactualist is open to the

30. The details surrounding this claim will differ according to one's preferred version of NeoMeinongianism. For Parsons (1980), possibilia are individuals corresponding to sets of nuclear (rather than extranuclear) properties; for Zalta (1983), they are individuals corresponding to sets of encoded (rather than exemplified) properties. The points I make in this paragraph, I believe, may be adapted to either a Zalta-esque or Parsonian version of Neo-Meinongianism. 
Neo-Meinongian. Shoemaker's Brownson, e.g., merely encodes personhood on this view. Yet it is this that allows Brownson to be intimately associated with the modal property possibly being a person; were Brownson spatiotemporal rather than abstract, thinks Zalta, Brownson would exemplify personhood.

But the trouble comes when one realizes what is entailed by the view that possibilia are entities individuated by the sets of properties to which they correspond. On a view like Zalta's, it seems as though Brownson would ultimately be an individual corresponding to a set of encoded properties, a set such as the following: \{being a person, having the body of a healthy person, having a brain which recently occupied a different body, being called Brownson ... \}. It thus follows that had Shoemaker decided to name the result of the hypothetical brain-transplant operation he discussed 'Robrown' instead, he would have all along been talking about a completely different possible individual than Brownson because the individual in question would have ultimately been one corresponding to a different set of properties. But being called Robrown rather than Brownson is not essential to the bit of possibilia in question; no matter what the individual is called in the thought experiment, we are all talking about the same possible individual when we tell our undergraduate students (during a discussion of personal identity) about this famous thought experiment. We are, one and all, talking about Shoemaker's creation.

The Neo-Meinongian might reply by claiming that we are indeed all talking about one and the same individual whenever we tell the basic story, accidental features aside, and that there are many sets that contain some minimal number of properties sufficient for determining that each corresponds to a possibilium that is deserving of the name 'Brownson'. Provided we are referring to an entity that corresponds to some set that includes is a person who recently survived a brain-transplant operation, say, we will be referring to Brownson. This sort of fix will not do, though, because it will thus turn out that 'Brownson' is a wildly ambiguous name. That is, some of the sets in question will include the accidental feature is called Brownson, others will include is called Robrown, etc., yet 'Brownson' would seemingly refer to all of the possibilia corresponding to each.

A view that is consistent with 'Brownson' behaving semantically like an ordinary proper name, that is, a view on which 'Brownson' refers to a unique individual if it refers at all, seems preferable here. And Modal Artifactualism is consistent with this sort of treatment of 'Brownson'. 
According to Modal Artifactualism, proper names like 'Brownson' refer to unique possibilia that are individuated by their historical properties (roughly, individuated by who created them), rather than individuals that are individuated set-theoretically. So, it seems that Neo-Meinongianism, unlike Modal Artifactualism, provides identity conditions for possibilia that are either too fine-grained to provide the correct results regarding the sameness of individuals from one thought-experiment to another, or too coarse-grained to account for the intuition that proper names, even when fictional, are not wildly ambiguous (whatever their content turns out to be). ${ }^{31}$

We should also note the difference between Modal Artifactualism and another close relative, the view known as Modal Fictionalism that was put forth by Gideon Rosen (1990). Rosen's view, like Modal Artifactualism, contends that modal discourse is ultimately to be understood as discourse about fictional entities. Specifically, he maintains that talk of possible worlds and their inhabitants should be understood as talk about what's "true according to" the modal theory David Lewis (1986) advocates known as Modal Realism. That is, we ought to treat Modal Realism as if it were a grandiose fiction. And so Rosen does, in a sense, accept the idea that possibilia just are fictionalia—the nonactual individuals Lewis' view would commit us to were it instead a true work simpliciter. But Rosen has a very different idea about the ontology of fictionalia from the Modal Artifactualist. He has the intuition that fictionalia are nonexistent, and endorses a commonsense sort of anti-realism. Rosen is no Neo-Meinongian; he believes fictionalia are nothing at all. This commonsense intuition, the one mentioned at the beginning of this paper, is the very motivation for his modal metaphysics. So if his intuition is correct, and if he can show that our discourse about possibilia is ultimately discourse about the "fictionalia" found "in the story of" Modal Realism, then it seems that he will have succeeded in showing that such discourse is ultimately about nothing at all (or perhaps it's about surrogates for fictionalia, whatever those turn out to be; or perhaps it's about whole fictions, whatever those turn out to be).

But serious doubts have been raised about whether or not Rosen's view is a tenable theory of modality. ${ }^{32}$ More to the point, however, if Modal

31. These objections are essentially modifications of some objections Thomasson gives to Neo-Meinongian views of fictionalia. See her 1999, $56 f$.

32. See, e.g., Fine $(2003,174-178)$, and Sider $(2002,34-39)$ for some very compelling criticisms of Modal Fictionalism. 
Fictionalism were a correct modal view, it would only follow that we would not be ontologically committed to possibilia of the sort envisaged by a possibilist. But what it would fail to demonstrate (what it in fact merely takes for granted) is that we wouldn't be committed to merely possible talking donkeys, 50-foot tall women, Brownson, Black's two spheres, and all the rest, in the sense of being committed to the Artifactualist fictionalia that serve as their surrogates. The Modal Fictionalist may have the initial intuition that these sorts of entities fail to exist, but given the soundness of van Inwagen's argument and the parallels between works of fiction and modal stories, that intuition should be abandoned.

\section{Replying to three worries}

I wish now to respond to three sorts of objections to Modal Artifactualism. The first runs as follows. Modal Artifactualism claims to provide us with the metaphysical resources to understand our talk about (Jackson's) Mary, (Shoemaker's) Brownson, and Black's iron spheres. We say they are possible individuals, but in doing so, we are allegedly just making a claim made true by the existence of some actual-world surrogate playing some appropriate theoretical role. And Modal Artifactualism further tells us that a sentence such as 'Mary is a brilliant neurophysiologist' is intelligible because there is some contingent abstracta created by Jackson that is the referent of 'Mary'.

But, the objection proceeds, those facts tell us nothing about Mary qua possibilia. That is, Modal Artifactualism (in response to Fine) tells us that 'Mary is a (merely) possible person' is literally false (because abstracta are not possibly people) and that this is no theoretical drawback (because Mary holds personhood), but this tells us nothing about how to understand sentences such as 'Possibly, Mary is a person' or 'Possibly, Mary exists'. These are true, of course, yet Modal Artifactualism provides no account of this. In virtue of what is Mary among the merely possible (people) rather than the impossible? These are precisely the sorts of answers we are owed in this context, because when doing thought experiments, of primary importance is whether or not the entities we are talking about are things that are ultimately possible or impossible.

My reply to this is the following. Modal Artifactualism is not aimed at providing a full-fledged, reductive account of modality itself. The view is simply concerned with providing acceptable (that is, at least actualistic) 
metaphysical underpinnings of our discourse about merely possible individuals. A theorist such as David Lewis, on the other hand, is someone who is concerned with providing a full-fledged, reductive account of modality. His (1986) thus provides a (possibilist) view on which 'Possibly, something is F' and 'Something is a possible F' are equivalent. But Modal Artifactualism offers no such translation schema. I say that 'Possibly, Mary is a person' is literally true, and so it is not equivalent to the literally false (as explained above) 'Mary is possibly a person'. The former sentence is true because 'Mary' refers to a contingent abstractum that fails to hold incompatible properties (that is, Mary holds properties that could be coexemplified).

Of course, this explanation of the truth of the sentence itself relies on modal notions, but this is no reason to reject Modal Artifactualism. As other prominent actualists have noted, we may take modality itself as primitive, and then provide an explanation of (concepts such as) possible individual that ultimately relies on this primitive concept that is a theoretically worthwhile explanation in virtue of the way it illuminates the overall modal picture. ${ }^{33}$ Modal Artifactualism allows us to learn much about how our modal notions are connected one to another, even if it does not allow us to explain modality itself in an ultimately non-circular way. It is not a view that can provide a recipe for determining when a contingent abstractum goes proxy for a possible or an impossible individual in a way that doesn't already rely on some understanding of modality, yet it is a view that positively informs our thinking about possible individuals (and other matters modal). We have quite a bit of insight into what makes for a consistent fiction, and we thus gain a fair amount of insight into the nature of possibilia. This is the most that we can ask of a theory that respects our actualistic leanings.

The second objection runs as follows. Modal Artifactualism is committed to the idea that we make up possible individuals as we go, and the view is committed to the idea that there is a one-to-one match-up for the possibilia and the contingent abstracta that are created by us. But that cannot be right; there are far too many possible individuals to be accounted for by our meager activities. The number of possibilia far outstrips the number of abstracta that could ever be created by us when we engage in our storytelling. There are possible individuals that no one has ever thought about or will ever think about.

33. Plantinga has a lengthy and helpful discussion of these matters in his (1974). 
Here is my reply to this worry. We are all (at least, we all ought to be) actualists. That is, none of us do (or should) believe that merely possible (i.e., nonactual) individuals exist already. Consequently, it would be wrongheaded to think that, according to Modal Artifactualism, when we tell a modal story, we are thereby creating individuals that go proxy for some already extant possible individual. That is, it would be a misconstrual of Modal Artifactualism and the ontological facts if one were to think that there are too many possible individuals out there for us to make up enough abstracta to account for them all. Rather, there is automatically enough abstracta to account for all the possibilia, because whenever we speak intelligibly about possible individuals, some abstracta automatically fills in the proper sort of role making our discourse intelligible. We must be clear on the central claim of Modal Artifactualism: the one-toone match-up proposed is identity-every possibilium just is a fictional individual. Hence, "each" entity necessarily comes into existence precisely when "the other" does.

The last sort of worry directly focuses on the claim made throughout this paper that Artifactualist fictionalia are well-suited to play the role of possibilia. It is thus a worry that indirectly is aimed at my further claim that Artifactualism gains credence because it provides this sort of modal service. Here is the objection. There is no unique possibilia role to be played by whatever entities one proposes; there are many such roles. Now, Modal Artifactualism proposes entities that, if serviceable at all, are able to fill in for the possible objects we talk and think about when performing philosophical thought experiments and entertaining counterfactual scenarios. That's all well and good, but there are other possibilia roles that are germane besides this one, others that must be played by the entities a modal theory commits us to if that theory is to gain credence through its serviceability, and Artifactualist fictionalia are ill-suited for those roles.

What are those alternate possibilia roles? While this is not intended to be an exhaustive list, let us at least consider three others that, traditionally, have been countenanced. (i) Possibilia are things to which we bear various relations and thereby make de re modal claims true or false. Thus, it is true of Barack Obama that he could have been born in Virginia (and not Hawaii), e.g., because there is some merely possible Barack Obama who is born in Virginia. (ii) Possibilia are the entities that make nested modal claims true. For instance, it seems as though "Possibly, Caesar had a sixth right finger which was never burnt but was such that, possibly, it 
was burnt" is a true sentence, and it is true, in part at least, because there exists some merely possible burnt Caesarian sixth right finger. ${ }^{34}$ (iii) Possibilia are things that make valid various formulas of quantified modal logic. For instance, the Barcan Formula:

$$
\text { BF: } \forall \mathrm{x} \square \mathrm{Fx} \rightarrow \square \forall \mathrm{x} \text { Fx }
$$

which, when translated to English, is equivalent to:

B: If it is possible that something is $\mathrm{F}$, then something is such that it is possible that it is $\mathrm{F}$

is valid because there are some merely possible objects that are non-identical to any actual object.

Now, the possibilist can provide an overall modal theory that relies on entities that are able to play roles (i)-(iii) in addition to the one role that the Modal Artifactualist has identified. Consider Lewis' Modal Realism. According to this view, nonactual possibilia are able to provide the grounding for the above claim about Obama because some flesh and blood, otherworldly Obama - not our Obama, but a counterpart of our Obama-is (there) born in Virginia (and not Hawaii). Moreover, "Possibly, Caesar had a sixth right finger which was never burnt but was such that, possibly, it was burnt" is made true by Modal Realist possibilia as well because there exists some nonactual (flesh and blood, otherworldly) finger that, in some nonactual world, is a burnt sixth right finger of (a six-fingered counterpart of our five-fingered) Caesar. And lastly, Modal Realism provides the nonactual possibilia that can make valid our formulas of quantified modal logic. BF, for example, turns out to be valid given that otherworldly concrete objects fail to be identical to any objects in our world (each concrete possibilium is "worldbound" and not "trans-world" according to Modal Realism).

Modal Artifactualism, it seems, is a modal theory that relies on entities that cannot plausibly play these three additional roles. Fictionalia, on this view, are our creations. As such, it seems implausible to hold that they can similarly ground de re modal claims, nested modal claims, and the formulas of quantified modal logic. For instance, it would be absurd to claim that

34. Alan McMichael (1983) is largely responsible for arguing that this is an important possibilia role and that actualist modal theories have a very difficult time delivering surrogates capable of playing this role. 
Obama is possibly Virginia-born because there exists some story told by us in which some fictional individual, viz., Obama, was born there! It's certainly not the case that our story-telling activities are responsible for grounding de re modal facts, and it's certainly not the case that every individual that figures in a modal narrative is (thereby) a fictional individual.

My response to this third worry is twofold. First, I admit that Modal Realism posits entities, viz., genuine (nonactual) possibilia, that are better-suited to play these possibilia roles than Artifactualist fictionalia. It is indeed a more straightforwardly serviceable modal view in this respect than Modal Artifactualism. However, I nonetheless maintain that it is still not epistemically preferable. Any modal theory that commits us to possibilism ought to be resisted on the basis of the sheer implausibility of its ontology. Now, I do not think that possibilist modal views such as Lewis' ought to be resisted at all costs, but if an actualistically acceptable rival exists, one ought to be an actualist instead. Any actualist view will automatically come at less of an ontological cost than any form of possibilism (while it won't be anywhere near free-contingent abstract individuals are, for instance, admittedly rather odd), and thus if some amount of sacrifice has to be made with respect to serviceability, then so be it. Serviceability is not the only desideratum to take into account.

Second, I maintain that Modal Artifactualism in fact provides just such an actualistically acceptable rival. It is a view that not only fails to rely on a wild ontology of nonactual individuals, it is a view that is serviceable to a high-enough degree. Artifactualism is not as robustly serviceable as Modal Realism, e.g., but it's at least serviceable in the way that I have argued for at length here. Moreover, it is not utterly silent about the relationship of fictionalia to the roles (i), (ii), and (ii) above, and in some cases, it is quite forthcoming.

As for (i): Modal Artifactualism was never intended to be a theory that provides the grounding for all our de re modal claims. That is, it was never put forth as a theory of what's necessary and possible for all extant individuals, e.g., Barack Obama, that may get "imported" into our modal stories. Rather, it's simply intended as a theory of merely possible individuals, and that turns out to mean that it's a theory that applies only to individuals that in the first instance are introduced via our modal storytelling. It is these individuals that are fictional, and these individuals that are then "exported" to the non-fictional world, so to speak. Obama is not a fictional individual - he was introduced into the world not by an author, but by his parents—although fictions can be told about him. The Modal 
Artifactualist may then say that the truth of de re modal claims about non-fictional, actual individuals such as Obama, then, is not determined by his holding of any properties in any story about him; rather, all and only the modal properties associated with him are the ones he has, and it is only these extra-fictional facts that make true (or false) any de re modal claims about Obama. ${ }^{35}$

As for (ii): Modal Artifactualism does have something positive to say about how to understand nested modal claims. Consider the specific example from above, due, as far as I am aware, to Takashi Yagisawa (2008). Now, Caesar himself has the following property: possibly having a sixth right finger that was possibly burnt, but because of the reasons just given regarding de re modal claims, we know that this is not due to the way Caesar figures into some fiction. It's possible that some finger be a possibly burnt sixth right Caesarian finger, however, because the individual in question here, viz., the possible sixth right finger of Caesar, is a fictional individual. That is, there was some modal story, one first told by Yagisawa when he gave this example of nested modality in order to discuss this possibilia role and advance our philosophical thinking, about a merely possible sixth right finger of Caesar that was possibly burnt.

Crucially, what Modal Artifactualism tells us is that we cannot think about nested modality without thinking about the goings-on in some modal story. With this case, we may gain insight into the modal features of the relevant individuals not by thinking about the truth of any de re claim about Caesar or any actual (flesh and blood, Caesarian) finger. Rather, we may gain modal insight by realizing that there is a property that is held by a fictional finger (that is, some contingent, abstract artifact) as a result of the storytelling activities of Yagisawa, specifically, being a possibly burnt right sixth Caesarian finger.

As for (iii): Artifactualist fictionalia do seem to me to be fairly ill-suited to provide the resources to explain the semantics of quantified modal logic.

35. Mary, however, is a fictional individual — she was introduced into the world by an author, viz., Frank Jackson — and as such, she both has and holds various modal properties that are relevant to the truth of de re modal claims about her. For instance, the following is true of Mary: she fails to have the property possibly being a person. However, the following is also true of her: she has the property possibly holding the property of seeing blue rather than red when first exiting her black and white laboratory. She has the latter property because Jackson is such that he could have told his story in a slightly different way than he in fact did. That is, if it were the case that Jackson had told a slightly modified version of his story, the following would have been true of Mary: she holds the property seeing blue rather than red when first exiting her black and white laboratory. 
An appeal to fictionalia of this sort would likely serve to only muddy the logical waters. That is, using contingent abstracta as the indices in our modal logical models would likely lead to much more confusion than clarity in the study of logic. Possibilia of the Modal Realist variety seem better suited for this role. Why? Well, given that Modal Realism says that reality is constituted by an actual world and an infinity of nonactual worlds, we have in Modal Realism a reality that provides a ready-made guide for understanding modal logic semantics.

But a reality that is ready-made in this way for the study of modal logic is not required to make valid our modal logical formulas. What we need to make valid our modal logic formulas are simply models with "actual and nonactual universes of discourse" (that is, sets), the entities "in" (that is, those that are members of) those universes, and some specified accessibility relations among those entities. What's in these logical universes may not have anything to do with the modal structure of reality at all. Specifically, it need not be the case that they are populated by actualia and nonactual possibilia-the entities in these universes could be pineapples or coffee mugs (or Artifactualist fictionalia!) for all that matters to logic, so long as some are designated "actual" and others "nonactual". So, to admit that Modal Realist possibilia can play this role is a hollow sort of victory for the serviceability of such a view. If the entities that Modal Realism relies on exist, then Modal Realism is serviceable in this regard, but even if they do not, we still have the means to make valid our quantified modal logic formulas.

So, whatever loss in serviceability Artifactualism cedes to a possibilist view such as Modal Realism with respect to (iii) does not seem to be a loss of serviceability that detracts from the central thesis defended in this paper. That is, given that it's a possibilia role that need not be played by any of the things that make a theory a modal theory, Modal Realism doesn't seem to gain much utility here (at least, no more than any theory that commits us to pineapples or coffee cups, for instance). The individuals that most any theory (modal or nonmodal) commits us to will be able to provide the same sort of modal logical service. ${ }^{36}$

36. One may complain here that I have missed the point. We are not merely interested in entities that may make valid the formulas of any old, perhaps wildly implausible, modal logic. BF, e.g., when faithfully translated into English is true, and thus the entities that make BF valid must be ones posited by a true modal theory. In reply, I say that whether or not BF-when translated into English-is true is beside the point. A logic can be a worthwhile theoretical tool and not fully mirror reality, so entities (like pineapples or coffee cups) posited by some view that doesn't truly reflect the modal structure of reality can still be entities that provide the same modal logical service under consideration that Modal Realism can provide. In other words, (iii) 


\section{Conclusion}

To sum things up: When all is said and done, the solution to the fictionalialpossibilia problem ought to be found in a theory of fictionalia and possibilia that is based on a sensible actualist ontology, is serviceable to a high-enough degree (i.e., is sufficiently illuminating regarding the nature of possible objects and their relation to fictional objects and the rest of reality), and lacks the drawbacks of the rival modal views that posit actualia as surrogates for possibilia. While I do not pretend to have provided in this paper a knock-down argument in favor of the conclusion that Modal Artifactualism is just such a theory, I hope that I have shown that it is a serious contender. For the reasons given here, I think it is the contender that is the most epistemically worthwhile. ${ }^{37}$

\section{REFERENCES}

Black, Max 1952: "The Identity of Indiscernibles". Mind 61, 153-164.

Braun, David 2005: "Empty Names, Fictional Names, Mythical Names". Nous 39:4, 596-631.

Bricker, Phillip 2006: "Absolute Actuality and the Plurality of Worlds". In: John Hawthorne (ed.), Philosophical Perspectives 2006, Metaphysics. Oxford: Blackwell, 41-76.

Cross, Charles 1995: "Max Black on the Identity of Indiscernibles". The Philosophical Quarterly 45:180, 350-360.

Davies, David 2007: "Thought Experiments and Fictional Narratives". The Croatian Journal of Philosophy 1:19, 29-45.

Donnellan, Keith 1966: "Reference and Definite Descriptions". The Philosophical Review 77, 281-304.

Fine, Kit 2003: "The Problem of Possibilia”. In: Michael Loux \& Dean Zimmerman (eds.), The Oxford Handbook of Metaphysics. Oxford: Oxford University Press, 161-179.

is an area in which the modal logical serviceability of the entities posited does not lend credence to the view that posits them qua modal view.

37. I would like to thank Alberto Voltolini, Stuart Brock, William Knorpp, Ted Sider, Patrick Fleming, Tom Adajian and an anonymous referee at Grazer Philosophische Studien for extremely helpful comments and criticism regarding earlier drafts of this paper. Discussion with Ted Sider and William Knorpp, especially, helped clarify in my mind the content of the first two worries, respectively, for Modal Artifactualism presented in the Section 6, while the extended discussion of the third worry is due primarily to the comments of the anonymous referee mentioned above. 
Jackson, Frank 1982: "Epiphenomenal Qualia”. Philosophical Quarterly 32, 127136.

Kripke, Saul 1973: Reference and Existence: The John Locke Lectures. Unpublished.

— 1980: Naming and Necessity. Cambridge, Mass.: Harvard University Press.

Lewis, David 1978: "Truth in Fiction”. American Philosophical Quarterly 15:1, 37-46.

- 1986: On the Plurality of Worlds. Oxford: Blackwell.

McMichael, Alan 1983: "A Problem for Actualism about Possible Worlds". Philosophical Review 92, 49-66.

Parsons, Terence 1980: Nonexistent Objects. New Haven: Yale UP.

Plantinga, Alvin 1974: The Nature of Necessity. Oxford: Clarendon.

Rosen, Gideon 1990: "Modal Fictionalism". Mind 99, 327-354.

Salmon, Nathan 1998: "Nonexistence”. Nous 32:3, 277-319.

Shoemaker, Sidney 1963: Self-Knowledge and Self-Identity. Ithaca: Cornell UP.

Sider, Theodore 2002: "The Ersatz Pluriverse". Journal of Philosophy 99, 279315.

Sorensen, Roy 1992: Thought Experiments. New York: Oxford University Press.

Thomasson, Amie 1999: Fiction and Metaphysics. New York: Cambridge University Press.

Van Inwagen, Peter 2001: “Creatures of Fiction”. Reprinted in: Peter Van Inwagen, Ontology, Identity, and Modality. Cambridge: Cambridge University Press, 37-56.

- 2003: "Existence, Ontological Commitment, and Fictional Entities". In: Michael Loux \& Dean Zimmerman (eds.), The Oxford Handbook of Metaphysics. Oxford: Oxford University Press, 131-157.

Voltolini, Alberto 1995: "Ficta versus Possibilia". Grazer Philosophische Studien 49, 1-30.

Yagisawa, Takashi 2008: "Possible Objects". The Stanford Encyclopedia of Philosophy (Fall 2008Edition), Edward N. Zalta (ed.), URL = <http://plato.stanford. edu/archives/fall2008/entries/possible-objects/>.

Zalta, Edward 1983: Abstract Objects. Dordrecht: Reidel. 